\title{
ALGUMAS CONSIDERAÇÕES SOBRE O DEBATE PERSA NAS HISTÓRIAS DE HERÓ- DOTO
}

\author{
Prof. Doutorando Luiz Mauricio Bentim da Rocha Menezes ${ }^{1}$
}

\begin{abstract}
Resumo: Tomaremos como objetos de investigação de nosso trabalho o Debate Persa que se encontra nas Histórias de Heródoto. Tal debate suscita uma discussão sobre as formas de governo e qual seria a mais adequada para se viver. A finalidade de tal estudo é verificar a relação não só do governo, mas também da alma do governante, analisando as posições dos debatedores e suas intenções para o estabelecimento de um novo governo persa.

Palavras-Chave: Histórias de Heródoto; Debate Persa; Formas de Governo.
\end{abstract}

As formas de governo quando estudadas dentro da ótica da filosofia política são tratadas basicamente de duas maneiras: (i) de maneira descritiva, descrevendo cada uma delas e dizendo em que se diferenciam; e (ii) de maneira prescritiva, onde se analisa qual é a melhor e se faz uma hierarquia dos valores de cada uma. Tanto a descrição como a prescrição de uma forma de governo vai possibilitar conhecê-la detalhadamente, podendo ainda ser comparada historicamente, dizendo-se como cada uma delas ocorre em diferentes épocas. Entretanto, somente a prescrição envolve um estudo minucioso dos valores envolvidos ao tratar de suas características, o que pode envolver formas de governo nunca antes ocorridas na história ou reunióes entre governos diferentes, de onde se tira o melhor da cada uma, em uma espécie de ideal ou utopia.

Forma de governo, ou regime político, é uma tradução, mesmo que insuficiente para a palavra grega politeía. A análise e a classificação de regimes como sujeitos de reflexão se faz antes mesmo do uso recorrente do termo politeía entre os gregos. Será esta noção "a origem de um duplo modo literário que consiste tanto em redigir a politeía de tal ou tal cidade, quanto a escrita sobre a politeía ideal" (BORDES 1982, p. 14). Entre os governos estudados, a tirania nos chama especial atenção por ser uma forma de governo ambígua 
ao ser amada e odiada por muitos. A palavra tirania não é de cunho grego, mas pode ser de origem oriental, mas propriamente lídia (URE, 1922, p. 134; ANDREWES, 1957, p. 21-22). Mas qual seria propriamente o caráter de uma pólis tirânica? Entre as formas de governo apresentadas pelos gregos, a tirania aparece como um problema. Entre elogios e ofensas, o governo tirânico sempre beirou entre os extremos morais da virtude humana. Para alguns, é só mais um tipo possível de governo, para outros, é metáfora plena da usurpação do poder. Seja qual for a interpretação, a tirania ainda pode ser encontrada em nossos tempos, muitas vezes escondida sobre o viés de outro nome. $\mathrm{O}$ que queremos atentar é para o cerne da tirania que se encontra, não no governo da pólis em si, mas na alma de seu governante, i. e., o tirano. Através do estudo do debate persa apresentado por Heródoto em suas Histórias (III.80-82), pretendemos melhor analisar a maneira como ele conduz o debate sobre as formas de governo e a importância de uma distinção na alma de quem governa.

O debate persa sobre as constituições (HERÓDOTO, Histórias, III, $80.82)^{2}$ está relacionado diretamente ao governo de Dario na Pérsia entre os séculos VI e V a.C. Segundo a inscrição de Behistun, Dario ascendeu ao trono por direito de nascimento e por vontade do deus masdeísta Ahura Mazda (KENT, 1950). A inscrição ${ }^{3}$ gravada no rochedo de Behistun (BALCER, 1987, p. 21 apud SILVA; ABRANCHES, 1997, p. 95) foi criada com o intuito de ressaltar o direito hereditário legítimo de Dario ao trono aquemênida, sendo o texto original do próprio Dario o qual foi por este ditado aos escribas e traduzido em diversas línguas para fins de divulgação (ASHERI, 2006, p. 77). Muito possivelmente Heródoto conhecia esse texto, senão diretamente, pelo menos indiretamente através de uma de suas traduções ou pela oralidade. O Livro III de suas Histórias narra os antecedentes históricos da época da subida de Dario ao poder, assim como o seu governo propriamente dito, sendo o debate persa peça central para a validação desse novo governo. $\mathrm{O}$ debate ocorre entre Otanes, Megabizo e Dario, onde estes discutem entre si qual seria o melhor tipo de governo a ser formado. Apesar de este ser um debate curto, ele implica em algumas dificuldades interpretativas que podem ser minimizadas se entendermos, primeiro, o momento histórico em que se encaixa e, segundo, seu status quaestionis. Feito isso, poderemos compreender

2 A nossa tradução é baseada na de Maria de Fátima Silva e Cristina Abranches Histórias, livro III (Lisboa: Edições 70, 1997). Utilizamos para o texto grego a edição estabelecida por Carolus Hude, Herodoti Historiae, Tomvs I (Oxford: Oford University Press, 1927).

3“O rochedo de Behistun encontra-se cerca de trinta quilômetros da atual região de Kermanshch, no Curdistão. A inscrição foi escrita em alfabeto cuneiforme, em persa antigo, neobabilônico e elamita, datando provavelmente de 519-518 a.C. e é a mais longa e notável das inscrições reais aquemênidas, redigidas entre 539 e 338 a.C". 
que o governo escolhido não passa de uma tirania, tipo de governo que traz diversos problemas para o entendimento grego do governante oriental.

Depois de uma campanha vitoriosa contra o Egito, Cambises, senhor da Pérsia, morre antes de conseguir voltar à pátria, cabendo a seu irmão Esmérdis assumir o trono. Este, no entanto, já havia sido assassinado por Prexaspes, a pedido do próprio Cambises. Para evitar qualquer tipo de revolta, Prexaspes mantém o ocorrido em segredo. Os magos resolvem aproveitar-se desta situação para armar um plano de usurpação, onde um mago de mesmo nome Esmérdis assumiria o poder por ser muito semelhante fisicamente a Esmérdis irmão de Cambises e filho de Ciro. Colocado o plano em ação, ele reina por sete meses, sendo desmascarado por Otanes no oitavo mês, conforme Heródoto (HERÓDOTO, Histórias, III, 67-68). De acordo com a inscrição de Behistun, Cambises matou em segredo seu irmão Bardiya, o mesmo que Heródoto chama de Esmérdis. Depois da partida de Cambises para o Egito, o mago Gaumata se faz passar por Bardiya e promove uma revolta incitando o povo contra Cambises, que vem a falecer posteriormente no Egito. Gaumata mata todos aqueles que conheciam Bardiya e ninguém se opõe a ele até a chegada de Dario. Este irá matar o mago Gaumata, tomar o reino dele e com o favor do deus Ahura Mazda se tornará rei, retomando o reino de sua família (DB I $\$ \$ 10-13)$.

Apesar da mudança nos nomes, a inscrição de Behistun e a narrativa de Heródoto são semelhantes no que tange os principais pontos. Devemos atentar para o fato de o usurpador ser um mago, ou seja, fazer parte de um dos seis clãs da Média (HERÓDOTO, Histórias, I, 101). Isso colocou automaticamente o poder da Pérsia nas mãos dos medos, uma retomada do poderio medo na Ásia anterior ao governo de Ciro. Tal fato é motivo suficiente para que Dario derrube o mago e restaure o governo nas mãos de um persa que, no caso, é ele mesmo. No entanto, seria a versão oficial de Dario, oferecida pela inscrição e utilizada para legitimar seu governo, a verdade por trás dos fatos?

Muitas vezes os fatos podem ser alterados pelo vencedor, mudando, dessa forma, a história a ser contada. Nada impede que o usurpador não seja um mago, como foi exposto acima, mas o próprio Dario. Há possibilidade de que não exista mago algum e que o irmão de Cambises, Esmérdis (ou Bardiya), tenha chegado ao trono e posteriormente sido destronado por Dario, que para justificar seu ato teria criado a história do pseudo Esmérdis. Dessa forma, tendo sido o novo governante pintado como alguém de fora da família aquemênida e caracterizado como um mago medo, Dario poderia facilmente legitimar seu governo através da usurpação. Asheri coloca o problema nos seguintes termos: 
A inscrição de Behistun é um texto de propaganda, cujo fim principal é apresentar Gaumata-Bardiya como um impostor, um usurpador e subversor do direito hereditário legítimo de Dario ao trono aquemênida. A verdade fatual pode ser bem diferente: que o usurpador seja Dario - um Aquemênida, certamente, mas do ramo secundogênito, que provavelmente nunca deteve o trono de Anshan. Tendo Cambises morrido sem filhos, Dario pode ter decidido eliminar o único pretendente legítimo, Bardiya ou Esmérdis, irmão de Cambises, e conquistar o trono com um golpe de estado. Não seria possível entender, de outro modo, a insistência de Dario sobre a legitimidade de seu poder (ASHERI, 2006, p. 25) ${ }^{4}$.

A partir da formulação da hipótese da usurpação do trono por Dario, passaremos para a análise do debate persa narrado por Heródoto. $\mathrm{O}$ fato do debate não constar na inscrição de Behistun em nada prova que este não ocorreu, apesar de que também nada possamos dizer no sentido contrário. Muitos historiadores tomam o debate como puramente ficcional. Não será esse o ponto que iremos assumir, mas antes de apresentarmos melhor a nossa hipótese gostaríamos de discutir brevemente duas outras possíveis hipóteses interpretativas.

A primeira diz que o debate seria baseado em tratado de algum sofista como Protágoras, Hípias, Antifonte ou Pródico. Tal obra exporia a classificação tripla dos governos: dos muitos, dos poucos e de um só. Essa discussão tão característica do V século, já seria bastante conhecida de Heródoto e poderia tê-lo influenciado no momento da composição de sua obra. Para Murari Pires,

Trata-se do horizonte mental do lógos helênico que o texto de Heródoto assim projeta sobre a história aquemênida. Ele transpira a ambiência dos fundamentos retóricos da sofística. Ele discute e teoriza pelo debate as formas que estruturam a política, já bem consciente da evolução democrática cujos princípios virtuosos (isonomia, liberdade, mérito e responsabilidade cívica) são resolutamente contrastados com os vícios despóticos e transgressores dos bárbaros (PIRES, 2011).

O debate refletiria o embate entre lógos e antilogía, discutindo as leis adequadas para o novo governo, sendo o argumento final de Dario uma

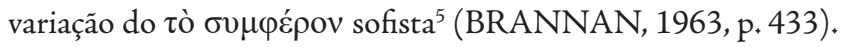

4 Ver também NYBERG, 1954, p.76-77 apud BRANNAN, 1963, p. 431:“a inscrição de Behistun é uma perspicaz ficção política. Dario teve que justificar sua subida ao trono. Ele empregou essa técnica de propaganda para fazer isso". Esta e demais traduções do inglês utilizadas nesse trabalho são nossas.

5 Contra ver: GAMMIE, 1986, p. 172-3: "O debate foi totalmente analisado recentemente por Helmut Apffel, que concluiu, apesar de outras coisas, que os discursos não refletem a influência dos sofistas, mas, com exceção do discurso de Otanes, voltam para a Pérsia original e para uma variedade de fontes da Iônia como também do continente grego". Grifos nossos. 
A segunda hipótese irá fazer uma comparação com a Atenas democrática do século V. No entanto, dificilmente a defesa que Otanes faz do governo do povo é semelhante à democracia ateniense da época de Péricles. Heródoto não usa o termo $\delta \varepsilon \mu о \kappa \rho \alpha \tau i ́ \alpha$ nas palavras de Otanes, mas ıбovo $\mu$ ín, o que pode representar, na verdade, uma crítica à democracia ateniense. Esta crítica pode ser melhor entendida se estabelecermos uma comparação com a descrição que Tucídides nos apresenta daquela época como no seguinte discurso de Cleon:

Muitas vezes no passado senti que a democracia é incompatível com a direção de um império, mas nunca tanto quanto agora, ao observar a vossa mudança em relação aos mitilênios. [...] vossa fraqueza vos expõe a perigos e não conquista a sua gratidão; sois incapazes de ver que vosso império é uma tirania imposta a súditos que, por seu turno, conspiram contra vós e se submetem ao vosso comando contra a sua vontade (TUCÍDIDES. História da Guerra do Peloponeso, III, $37)$.

Tucídides demonstra os problemas enfrentados pela democracia ateniense que em alguns casos pode parecer, no seu modo de agir, com uma tirania. Dario, em seu discurso, defende o monarca como o melhor entre os homens, o que faz com que ele tenha com este uma distinção do inconstitucional tirano (WEBSTER, 1948, p. 51). Se entendermos que o debate sobre as constituições tem um cunho filosófico, tomado por muitos comentadores como o "início da filosofia política grega" (HOW; WELLS, 1928, v. I, p. 278 apud FERRILL, 1978, p. 393, n. 28), poderemos entender que o que Heródoto está a fazer nesse debate não é apenas um relato persa, mas uma investigação sobre qual é a melhor forma de governo ${ }^{6}$.

O primeiro a falar será Otanes que defenderá a isonomía através do

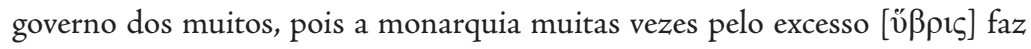
crescer a inveja [ $\varphi \theta$ óvo $\varsigma$, própria da natureza humana do homem desde que ele existe. No entanto,

um homem dado à tirania não devia conhecer a inveja, uma vez que

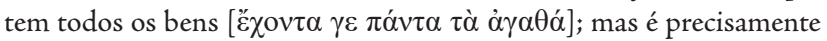
o contrário que grassa nas suas relações com os cidadãos - inveja os melhores enquanto vivem e estão à sua beira, e regozija-se com os piores, sempre pronto a dar ouvidos às calúnias; [...] adultera as

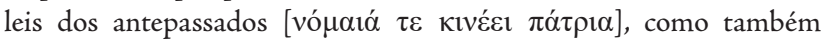
violenta as mulheres e até condena à morte sem prévio julgamento.

6 Segundo Bordes (1982, p. 249), “Nós devemos nos contentar de ver nesse texto de Heródoto uma das primeiras manifestações de uma reflexão sistemática estreitamente ligada à Atenas". 
[...] Exponho-vos, pois a opinião de que, recusando a monarquia, é o povo que devemos exaltar, porque é em comum [Kotvóv], na unidade

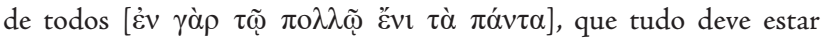
(HERÓDOTO, Histórias, III, 80, 4-6).

Megabizo irá acordar com Otanes quanto ao tirano, mas não concordará com o governo dos muitos, defendendo em seu lugar a oligarquia. Pois sair da býbris do tirano para cair na hýbris do povo não é aceitável.

É que, se o primeiro dos dois, o tirano, faz alguma coisa, fá-la com plena consciência do que está a fazer [ $\gamma \nu \omega ́ \sigma \kappa \omega \nu ~ \pi o \imath \varepsilon ́ \varepsilon 1]$; enquanto o

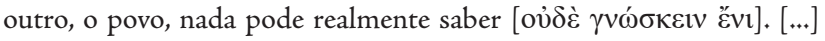
Que usem, pois, as capacidades governativas do povo todos aqueles que desejam mal aos Persas, e só esses; nós cá, por nosso lado, elejamos uma assembleia escolhida entre os melhores homens [ $\alpha \dot{\nu} \delta \rho \tilde{\omega} v \tau \tilde{\omega} v$

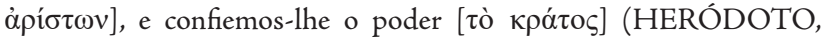
Histórias, III, 81, 2-3).

Dario irá considerar que das três alternativas apresentadas democracia, oligarquia e monarquia, somente a última supera as demais (HERÓDOTO, Histórias, III, 82, 1). Pois na oligarquia a disputa pelo destaque entre os melhores acaba por gerar o homicídio, dando lugar à monarquia (HERÓDOTO, Histórias, III, 82, 3). Quando o povo vem a governar, é impossível não haver divergências, e as inimizades criadas acabam por mover à conspiração, levando o homem mais admirado pelo povo ao poder, constituindo uma monarquia (HERÓDOTO, Histórias, III, 82, 4). Segundo Dario:

Nada poderá parecer melhor do que um só homem a governar, desde

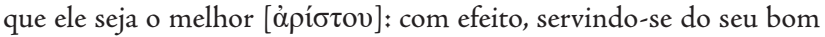
senso, tão excelente quanto ele próprio, poderá porventura governar o povo sem merecer censura, e melhor poderão assim ser silenciadas as decisões tomadas contra os opositores (HERÓDOTO, Histórias, III, 82, 2-3).

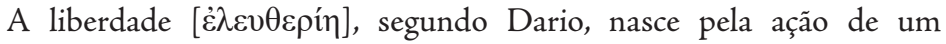
só homem e, por isso, se deve respeitar as leis dos antepassados [ $\pi \alpha \tau \rho i ́ o v \varsigma$ vónovs] mantendo-se a monarquia (HERÓDOTO, Histórias, III, 82, 5). Ferrill (1978, p. 397) em seu estudo sobre a tirania em Heródoto defende

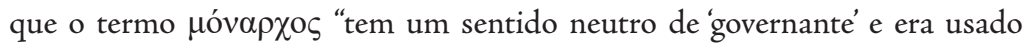
por Heródoto de maneira intercambiável tanto com $\beta \alpha \sigma ı \lambda \varepsilon v ́ s$ como com túpavvos". O termo túpavvos, por outro lado, não é um sinônimo de 
$\beta \alpha \sigma i \lambda \varepsilon v ́ \varsigma$, ao contrário do que diz a maioria dos comentadores de Heródoto, já que, segundo Ferril (1978, p. 395), há nas Histórias uma clara distinção entre estes dois termos 7 . Segundo diz (1978, p. 395), "não se pode afirmar que Heródoto era tão fortemente oposto à monarquia que não tenha feito distinções entre o tirano e o monarca. $\mathrm{O}$ debate persa acima citado demonstra que ele fez a distinção". Dessa forma, parece certo que a defesa de Dario é pelo melhor governo de todos e que, perante todos os argumentos apresentados, este só pode ser a monarquia.

De acordo com Struve, Heródoto teve acesso a fontes persas, mesmo que indiretamente, para compor os três discursos sobre os regimes políticos, sendo isso atestado pela comparação dos discursos, principalmente o discurso de Dario, com a inscrição de Behistun. (STRUVE 1948, p. 12-35 apud ASHERI 2006, p. 91). Asheri, a partir dos estudos de Struve irá concluir que

é incontestável que Heródoto conhecesse perfeitamente os ideais monárquicos de Dario: o papel decisivo do intelecto, o princípio da justiça imparcial, o critério da verdade, a monarquia como força mediadora entre extremos. Mas é igualmente necessário notar que essas ideias genéricas e usuais estão presentes nas propagandas monárquicas de todos os tempos e também na literatura grega de época arcaica. (ASHERI, 2006, p. 95)

Há, consequentemente, um ardil no discurso de Dario que permite que ele persuada os outros dois participantes. Tal artimanha pode ser identificada da seguinte maneira: ao fazer seu discurso, Dario contrasta o melhor homem com o pior, a liberdade com a arbitrariedade, o bom senso com a hýbris, o monarca com o tirano, defendendo para isso os pátrioi nómoi. Parece tudo bem ajustado e correto: o monarca ao ter bom senso liberta os homens do jugo do tirano por ser ele o melhor. Mas, o que devemos nos perguntar é o

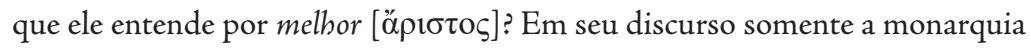
é a melhor porque tem o melhor homem. Se investigarmos a inscrição de Behistun, veremos que Dario é o rei porque é o escolhido de Ahura Mazda. Isso legitima a sua realeza, mas será que serve como critério para se determinar o melhor homem? Dario em seu discurso cria um dualismo que contrasta a monarquia em três momentos: primeiro com o seu outro que é a tirania, depois com a oligarquia e por último com a democracia. No entanto, podemos entender que cada um dos três tipos de governo pode ter seu melhor e seu pior, o que não é dito em seu discurso. Dario parece indicar que dentre os melhores homens é possível fazer uma distinção de alma que determina o melhor

7 "Heródoto não usa o termo basileús para se referir aos tiranos gregos". 
governante. Somente este único homem é capaz de governar melhor perante todos os outros, o que legitima a monarquia como sendo o melhor governo. É notório que Dario está fazendo uma distinção de alma entre os homens para que se possa dar o exercício do governo, pois, do contrário, se não houvesse tal distinção, todos os governos seriam possíveis, o que não o permitiria defender a monarquia como melhor entre todos os outros tipos de governo.

Otanes, ao contrário, é único que não defende um governo do(s) melhor(es), mas sim um governo do koinón, já que, segundo diz com relação à

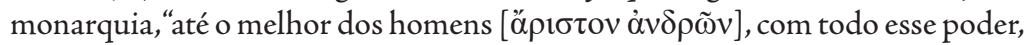
ficaria fora dos limites do seu juízo habitual” (HERÓDOTO, História, III, $80,3)$. Essa crítica vai de encontro ao que Dario defende quando supõe existir um áristos capaz de melhor governar. Otanes julga que todo homem, por melhor que ele seja, ao ter todo o poder para si irá se transformar num tirano. Isso indica que o tirano não é um problema de caráter propriamente, mas um mal do desejo que compóe a alma humana. Por isso, a única possibilidade para se ter um bom governo é o koinón, que constrói nos muitos a unidade de todos

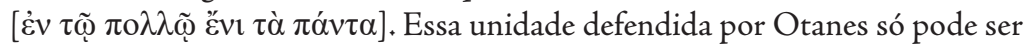
alcançada através da isonomia, palavra grega que indica um poder de direito (BORDES, 1982, p. 240), igual para todos os que participam desse governo koinón. Segundo Bordes,

O sinal é, além do fato de que a igualdade será um dos critérios clássicos da democracia, o emprego da isonomia na discussão sobre os regimes, onde Heródoto faz do termo o nome mesmo da democracia,

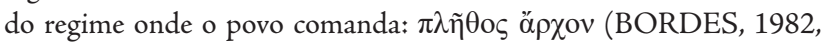
p. 240).

É notório que Dario no debate está construindo os alicerces para assumir o poder, seja pela palavra ou pela força, vide os exemplos de homicídio e conspiração que não apenas foram citados em seu discurso como efetivamente praticados se levarmos em consideração a usurpação contra o mago medo. Ao assumir a monarquia naquele momento, Dario estaria levando o governo para uma posterior tirania. Se olharmos por esse lado, poderemos notar que o discurso de Otanes, e a defesa da isonomia, é aquele que melhor combate os valores da tirania ${ }^{8}$.

É interessante notar que Heródoto afirma antes que os discursos

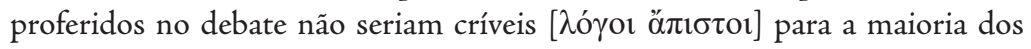

8 Segundo Asheri (2007, p. 474), “o adjetivo íóvouo ocorre em um famoso escólio ático dos tiranicidas do final do sexto século e indica a liberdade como oposta à tirania. [...] É provável que

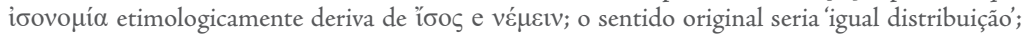
parece que somente depois o termo seria entendido como 'igualdade perante a lei', como derivado

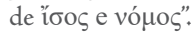


gregos, mas que eles realmente teriam ocorrido (HERÓDOTO, História, III, 80, 1-2). Pensar que um outro povo, afastado culturalmente dos gregos, tenha sugerido um modelo para o que veio a se tornar a democracia é romper com todos os paradigmas helênicos até então. A relevância do debate persa é a maneira como ele apresenta os diferentes modelos de governo, dos muitos, dos poucos e de um só, sobre o contraste de olhares dos príncipes persas. "Entre virtudes democráticas e excelência do governo, o Oriente dava lições para quem declinasse o vocabulário da pólis e seus derivados" (LIMA, 2008, p. 78). A oposição de discursos existentes torna rica não só a descrição de cada modelo, como também faz a defesa e a crítica de cada um deles, enriquecendo com detalhes e valores a composição do debate.

O Debate Persa é um marco para as discussóes existentes sobre as formas de governo. Sua distinção entre governo dos muitos, dos poucos e de um só, trás a problematização dessas possíveis constituições e suas considerações para se determinar o melhor governo. $\mathrm{O}$ intuito de Heródoto é construir em suas Histórias um debate que irá determinar de maneira deliberativa a forma de governo a ser seguida entre os persas. A proposta de Dario irá fazer uma distinção de alma entre os tipos de governantes, entendendo que a monarquia é o melhor governo por ter o melhor dos homens. Em contraste, Otanes irá apresentar o tirano como uma necessária deturpação do monarca, pois mesmo tendo todos os bens [ $\pi \alpha ́ v \tau \alpha \tau \grave{\alpha} \alpha \dot{\alpha} \gamma \alpha \theta \dot{\alpha}]$ irá invejar os demais na sua necessidade de ter sempre mais. $\mathrm{O}$ tirano aparecerá nesse momento como um verdadeiro problema para o governo. Seria possível evitar que um rei se tornasse um tirano?

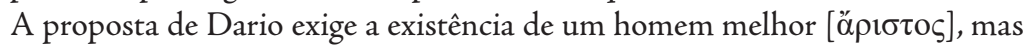
não traz nenhuma referência de como um homem poderia atingir esse estágio, o que torna insipiente a sua colocação da monarquia como o melhor governo. Isso nada mais é do que uma artimanha para se tomar o poder sobre os demais, tomando a devida precaução de justificar seu governo diante do povo pela propaganda da inscrição de Behistun.

\title{
SOME CONSIDERATIONS ON THE DEBATE OF THE PERSIANS IN HERODOTUS' HISTORIES
}

\begin{abstract}
In our work, we take as objects of investigation the Persian Debate lying in the Herodotus' Histories. This debate raises a discussion about the forms of government and which would be the most adequate to live. The purpose of such study is to verify the relationship not only of the government but also of the soul of the ruler, analyzing the positions of the debaters and their intentions for the establishment of a new Persian government.

Keywordsः Herodotus' Histories; Persian Debate; Forms of Government.
\end{abstract}




\section{Bibliografia}

Edições, traduções e comentários das Histórias de Heródoto

ABRANCHES, Cristina. SILVA, Maria. F. , Heródoto: Histórias, livro 1. Tradução e Notas de Cristina Abranches e Maria de Fátima Silva. Lisboa: Edições 70, 1997.

ASHERI, David. LlOYD, Alan. CORCELlA, Aldo. A Commentary on Herodotus Books I-IV. Oxford; New York: Oxford University Press, 2007.

HUDE, Karl. Herodoti Historiae, Tomvs I. recognovit brevique adnotatione critica instrvxit: Carolvs Hude. Oxford: Oford University Press, 1927.

\section{Estudos}

ASHERI, David. O Estado Persa. Ideologias e Instituições no Império Aquemênida. Tradução de Paulo Butti. São Paulo, Perspectiva, 2006.

BIGNOTTO, Newton. O Tirano e a Cidade. São Paulo: Discurso Editorial, 1998. BOBBIO, Norberto. A Teoria das Formas de Governo. Tradução de Sérgio Bath. Brasília: Editora Universidade de Brasília, 1980.

BORDES, Jacqueline. Politeia dans la pensée grecque jusqu'a Aristote. Paris: Les Belles Lettres, 1982.

BRANNAN, Patrick. T. Herodotus and History: The Constitutional Debate Preceding Darius' Accession. Traditio, v. 19, p. 427-438, 1963.

FERRILL, Arther. Herodotus on Tyranny. Historia: Zeitschrift für Alte Geschichte, v. 27, n. 3, p. 385-398, 1978.

GAMMIE, John. G. Herodotus on Kings and Tyrants: Objective Historiography or Conventional Portraiture? Journal of Near Eastern Studies, v. 45, n. 3, p. 171-195, 1986.

GUTHRIE, William. K. C. Os Sofistas. Tradução de João Rezende da Costa. São Paulo: Paulus, 2007 (1995, $1^{\text {a }}$ ed.).

KENT, Roland. G. Old Persian. Grammar. Texts, Lexicon. New Haven, Connecticut: American Oriental Society, 1950.

LIMA, Paulo. B. Progymnasia Basileias. L'impero persiano e l'immagine pastorale nella riflessione politica antica. In: PANI, Mario. (a cura di). Epigrafia e territorio. Politica e società. Bari: Edipuglia: 2007, p. 273-289.

72-78, 2008.

. Teria o Oriente inventado a Democracia? Revista UFG, v. 10, n. 4, p.

PIRES, Francisco M. Heródoto: Mithistória do Debate Persa. In: PIRES, Francisco. M. Tucídides entre Maquiavel e Hobbes I: $\mathrm{O}(\mathrm{s})$ Olhar(es) da História e as Figurações do Historiador (Modernidades Tucidideanas II, 2011, inédito, não publicado, Registro BN 534.282). Disponível em: <http://www.fflch.usp.br/dh/ heros/FMP/DebatePersa.htm >. Acesso em 19 de setembro de 2012.

TUCÍDIDES. História da Guerra do Peloponeso. III.37. Tradução de Mario da Gama Kury. (4 ed.). Brasília: Editora Universidade de Brasília, Instituto de Pesquisa de Relações Internacionais; São Paulo: Imprensa Oficial do Estado de São Paulo, 2001.

URE, Percy. N. The Origin of Tyranny. Cambridge: Cambridge University Press, 1922.

WEBSTER, Thomas. B. L. Political Interpretations in Greek Literature. Manchester: Manchester University Press, 1948. 